\title{
Evaluation of the Effect of Zirconia and Ti- tanium Abutments on Microleakage of Im- plant-Abutment Interface Under Oblique Cyclic Loading In Vitro
}

\author{
SH Naser mostofy ${ }^{1}$, A Zarbakhsh ${ }^{1}$, MM Alaei $^{2}$, T Bitaraf $* 3$
}

1- Assistant professor, Prosthodontics Dept, Dental Faculty, Tehran Medical Sciences, Islamic Azad University, Tehran, Iran.

2- Postgraduate student, Prosthodontics Dept, Dental Faculty, Tehran Medical Sciences, Islamic Azad Universi-

ty, Tehran, Iran

3- Assistant professor, Dental Implant Research Center, Dental Faculty, Tehran Medical Sciences

\begin{tabular}{l}
\hline ARTICLE INFO \\
\hline Article History \\
Received: Apr 2020 \\
Accepted:May 2020 \\
ePublished: Jun 2020 \\
\hline Corresponding author: \\
T Bitaraf,Assistant pro- \\
fessor, Dental Implant \\
Research Center, Dental \\
Faculty, Tehran Medical \\
Sciences \\
Email:taherehbitaraf@ \\
yahoo.com
\end{tabular}

\section{Introduction:}

Microleakage through the gap at the implantabutment interface (IAI) is still one of the challenges of two-piece implant treatment. ${ }^{(1-8)}$ In an in-vitro study, the prevalence of microleakage in Morse taper implants was reported to be $20 \%{ }^{(9)}$ All two-piece implant systems include two main parts of endosteal fixture and prosthesis-supporting abutment. ${ }^{(10-12)}$ Inevitably, in all two-piece implants, the gap size increases or decreases during

\begin{abstract}
Background and Aim: Oral bacteria can proliferate in the implant-abutment interface (IAI) and cause inflammation in the peri-implant tissues and adjacent bone. This study aimed to assess the effect of zirconia and titanium abutments on the microleakage of the IAI under oblique cyclic loading conditions.

Materials and Methods: In this in-vitro study, 12 implant-abutment assemblies with zirconia and titanium abutments, in two groups of six, were vertically mounted inside resin blocks modified with autopolymerizing polyester base. The specimens were subjected to $75 \mathrm{~N}$ oblique cyclic loading at an angle of $30 \pm 2^{\circ}$ to the longitudinal axis of the implant at a frequency of $1 \mathrm{~Hz}$ at 500,000 cycles, which is equivalent to 20 months of human masticatory force. Fuchsine solution was used to evaluate the microleakage. To examine the penetration of fuchsine into the IAI, the fixtures were cut from the middle using a cutting machine. Then, the amount of fuchsine penetration in each of the samples was measured with a stereomicroscope at $\times 75$ magnification at three points in each semicircle (cut implant), and the average of these six points was recorded as microleakage $(\mu \mathrm{m})$. T-test was used to compare the microleakage after load with the significance level set at 0.05 .

Result: The microleakage rate after cyclic loading was $66.08 \pm 11.66 \mu \mathrm{m}$ in zirconia abutments and $39.17 \pm 10.65 \mu \mathrm{m}$ in titanium abutments, which was significantly higher with zirconia abutments $(\mathrm{P}=0.002)$.

Conclusion:Microleakage after oblique cyclic loading varies depending on the type of abutment. Titanium abutments showed significantly less microleakage than zirconia abutments.

Keywords: Dental Implants, Dental Leakage, Abutment, Zirconia, Titanium
\end{abstract}

\section{J Res Dent Maxillofac Sci 2020;5(3):15-23}

the application of force to the assembly, which leads to a pumping effect. ${ }^{(13-15)}$ The pumping effect is the passage of fluids when the implant is subjected to functional forces, which increases the concentration of bacterial metabolites in the peri-implant area. ${ }^{(16)}$

Factors that affect the microleakage include the implant system used, the geometry of the IAI, the precision of fit, micromovements, the applied torque, and occlusal forces..$^{(16-20)}$ 
In the event of microleakage, deep pockets containing anaerobic bacteria form around the implant within 3-6 months. ${ }^{(21)}$ Following the pocket formation, bacterial adhesion, increased bacterial byproducts, and finally, pre-implant boneloss will occur, which are the primary cause of long-term failures in the implant. ${ }^{(21-23)}$

Various techniques have been proposed to reduce microleakage, including the use of different types of implant-abutment connection, the use of silicone gel sheets, application of different torques to connect implants and abutments, and the use of different types of abutment ${ }^{(23-25)}$ The material of the abutment has a definite effect on the aesthetic appearance and function of an implant restoration. ${ }^{(26)}$ Titanium abutments are considered as the gold standard in implant reconstructions due to their good stability and acceptable biocompatibility. ${ }^{(26)}$ Recently, however, the aesthetic needs of patients to reconstruct a single-tooth space by implant-based restoration, especially in anterior areas, have challenged clinicians. ${ }^{(27,28)}$ The introduction of modern high-strength ceramic abutments has provided a new opportunity for the restoration of missing teeth in the esthetic zone. (26) So far, various bacteria or dyes such as fuchsine, rhodamine $\mathrm{B}$, and toluidine blue, have been used to measure microleakage in crowns, composite restorations, and IAIs. $\left.{ }^{(3,29,30}\right)$ Smith and Turkyilmaz evaluated the sealing capability of titanium and zirconia abutments with two different screw torque values against Porphyromonas gingivalis, Prevotella intermedia, and Fusobacterium nucleatum. ${ }^{(23)}$ They showed that in titanium abutments, changing the amount of torque from 20 N.cm to 35 N.cm would not have a significant effect on microleakage. It was generally reported that titanium abutments show smaller microgaps compared to zirconia abutments but tightening zirconia abutments from $20 \mathrm{~N} . \mathrm{cm}$ to $35 \mathrm{~N} . \mathrm{cm}$ reduces the size of the microgap. ${ }^{(23)}$ Abdelhamed and colleagues compared the microleakage of the IAI in two types of abutments, zirconia and titanium, in non-loading conditions. ${ }^{(31)}$ They stated that time, type of abutment, and amount of torque play a key role for leakage from the internal chamber of the implant to the external milieu while for leakage from the external milieu to the internal chamber, only two factors of time and type of abutment are effective. ${ }^{(31)}$ Several studies have examined the factors affecting screw loosening, ${ }^{(1,2,4,6,7)}$ but little information is available on the effect of abutment type on microleakage. ${ }^{(4,24)}$ Therefore, this study evaluated the effect of two types of abutments, zirconia and titanium, on the microleakage of the IAI under oblique cyclic loading in vitro.

\section{Materials and Methods:}

This in-vitro experimental study was performed to assess the microleakage of the IAI under oblique cyclic loading in zirconia and titanium abutments at the Prosthodontic and Implant Department of the Faculty of Dentistry of Islamic Azad University of Medical Sciences, Tehran, Iran.

The implant system used was the Osstem implant (Osstem Co., Seoul, South Korea) with the $11^{\circ}$ Morse taper contact area geometry. Because this type of implant-abutment connection is mostly used today, it was also considered in this research. ${ }^{(7,11)}$ The 12 zirconia and titanium abutments were all straight with a diameter of 4.5 $\mathrm{mm}$, a gingival height of $5 \mathrm{~mm}$, and a height of $7 \mathrm{~mm}$. The 12 implants had a length of $10 \mathrm{~mm}$ and a diameter of $4 \mathrm{~mm}$ and were all made of titanium.

First, the implants were mounted vertically inside resin blocks modified with autopolymerized polyester base (Technovit 4000; Heraeus Kulzer GmbH \& Co., Wehrbein, Germany) with a length of $19 \mathrm{~mm}$ and a diameter of $34 \mathrm{~mm}$ (Figures 1 and 2). ${ }^{(27,31)}$

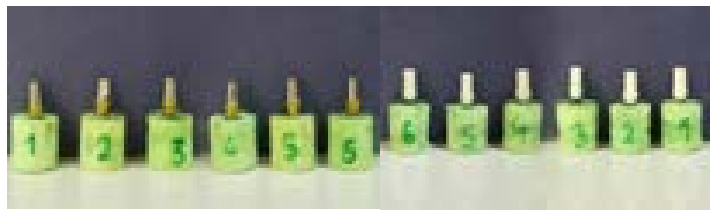

Figure 1-Mounted specimens of zirconia abutments (left) and titanium abutments (right). 


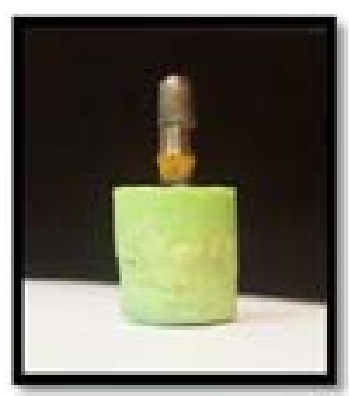

Figure 2: Mounted sample with a cemented steel cap

This resin had a coefficient of elasticity of 12 $\mathrm{GPa}$, which is similar to the coefficient of elasticity of bone tissue $(13.7 \mathrm{GPa})$. To prepare this resin, the powder and liquid were mixed in the same manner for all samples, according to the manufacturer's instructions. ${ }^{(31)}$ To increase the accuracy of the vertical mounting of implants inside the blocks, a dental surveyor (J.M. Ney Co., Bloom field, CT, USA) was used.(6) In the next step, 12 mounted implants were randomly divided into two groups (6 in each group). ${ }^{(3)}$ Six zirconia abutments were installed for group one and six titanium abutments for group two. ${ }^{(3)}$

To increase the accuracy of the work, one operator performed all steps. ${ }^{(31)}$ The abutments were fastened using a digital torque meter (Lutron Electronic Enterprise Co., Taiwan) with a torque of $30 \mathrm{~N} . \mathrm{cm}$, according to the recommendation of the manufacturer. ${ }^{(7,11)} \mathrm{Ten}$ minutes later, all samples were retorqued with $30 \mathrm{~N} . \mathrm{cm} .{ }^{(4)}$ This has been recommended in many articles to compensate for the settling effect and achieve optimum preload. ${ }^{(17)}$ Each sample inside the jig was held by a plastic or polymer holder at an angle of $30 \pm 2^{\circ}$ according to ISO $14801 .^{(4,7)}$

In this study, a cyclic loading device (Chewing Simulator CS-4, Mechatronik, Germany) was used to simulate human masticatory forces. $(4,5)$ A $75 \mathrm{~N}$ force at a $1 \mathrm{~Hz}$ frequency in $500,000 \mathrm{cy}-$ cles, which is equivalent to 20 months of average human masticatory force, was periodically applied to the implant-abutment assembly at an angle of $30^{\circ}$ and a distance of $11 \mathrm{~mm}$ from the implant support level by the device (Chewing Simulator CS-4, Mechatronic, Germany). Also, according to ISO 14801, the loading point distance from the implant support level was $11 \mathrm{~mm}$.
(4) For this purpose, 12 semi-spherical stainless steel caps were made according to the form of the abutments and were cemented on the abutments with temporary cement (Temp bond, Kerr, America) and a force of $15 \mathrm{~N} .{ }^{(4)}$ Therefore, the specimens were subjected to $75 \mathrm{~N}$ oblique loading at an angle of $30 \pm 2^{\circ}$ to the longitudinal axis of the implant at a frequency of $1 \mathrm{~Hz}$ in 500,000 cycles, which is equivalent to 20 months of human masticatory force (Figure 3). ${ }^{(4)}$

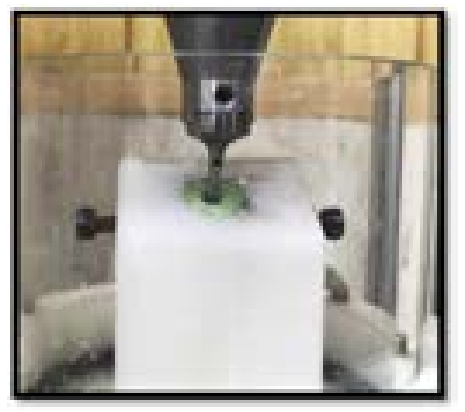

Figure 3: Sample under force application

To evaluate the microleakage from the outside into the IAI, fuchsine solution (Fuchsine, Merck, Germany), $0.5 \%$ by weight $(0.5 \%$ basic fuchsine), was used. ${ }^{(30)}$ For this purpose, the upper surface of the contact of the abutments was first sealed with a layer of rose wax and a layer of nail polish so that the fuchsine solution did not penetrate the abutments from above. Fuchsine solution was prepared according to the factory instructions. All samples were immersed in this solution and incubated at $37^{\circ} \mathrm{C}$ for 24 hours, and then, the samples were removed. ${ }^{(4,30)}$

To evaluate the microleakage, the abutment screw was removed using a wrench, and the abutments were separated from the fixture. To investigate the penetration of fuchsine into the IAI, the fixtures were cut from the middle using a cutting machine (Mecatome T-201A, Presi France). ${ }^{(4)}$ Then, the penetration of fuchsine in each of the samples was measured with a stereomicroscope at $\times 75$ magnification (Nikon, SMZ800N, Japan) at three points of each semicircle (cut implant). The average of these six points was recorded as the microleakage of each sample in microns $(\mu \mathrm{m}){ }^{(4,6)}$ 
Statistical Analysis:

In this study, one person blindly performed all laboratory operations under the same conditions to prevent measurement bias and to avoid confounding variables such as the amount of force applied, angle of force applied, frequency of applied force, number of cycles, loading point distance to the surface of the cylinder, and the placement angle of the implant-abutment). All the factors related to the abutment and implant were the same in all samples.

According to the results of the study by Abdelhamed et al ${ }^{(31)}$ and using the power option of one-way analysis of variance (ANOVA) in PASS 11 software, considering $\alpha=0.05, \beta=0.2$, the average difference of 3 units, and the mean standard deviation (SD) of 16, the minimum sample size in each study group was selected to be six samples. For statistical analysis, considering that the data followed a normal distribution according to the Kolmogorov-Smirnov test, t-test was used to compare microleakage after load. All tests were performed in SPSS (Version 22; SPSS Inc., Chicago, IL, USA) with the significance level set at 0.05 .

\section{Results:}

In this study, 12 implant-abutment assemblies, including six zirconia abutments and six titanium abutments, were compared in terms of microleakage after force application. The average amount of microleakage in the samples after cyclic loading is shown in Table 1 and Figure 4.

Table 1. Statistical results of the average microleakage after oblique cyclic loading in the samples

\begin{tabular}{lll}
\hline Group & $\begin{array}{l}\text { Sample } \\
\text { number }\end{array}$ & Microleakage $(\mu \mathrm{m})$ \\
\hline \multirow{4}{*}{ Zirconia } & 1 & 56.876 \\
\cline { 2 - 3 } & 2 & 64.815 \\
\cline { 2 - 3 } & 3 & 53.930 \\
\cline { 2 - 3 } & 4 & 72.353 \\
\cline { 2 - 3 } Titanium & 6 & 62.587 \\
\hline \multirow{4}{*}{} & 1 & 85.964 \\
\cline { 2 - 3 } & 2 & 31.454 \\
\cline { 2 - 3 } & 3 & 49.690 \\
\cline { 2 - 3 } & 4 & 28.557 \\
\cline { 2 - 3 } 5 & 44.661 \\
\hline
\end{tabular}

The mean and SD for microleakage after cyclic loading was $66.08 \pm 11.66 \mu \mathrm{m}$ in the zirconia group and $39.17 \pm 10.65 \mu \mathrm{m}$ in the titanium group, which were compared in Table 2 and Diagram 1.

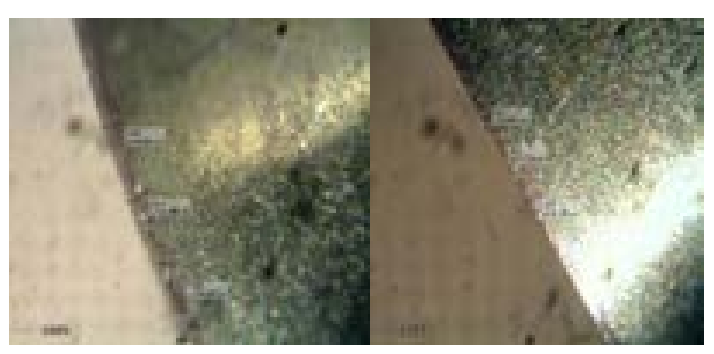

Figure 4b: Fuchsine penetration in samples of zirconia abutment group at $\times 75$ magnification of electron microscope

Based on the results of t-test (Table 2), it was found that the amount of microleakage following oblique cyclic loading in the group of zirconia abutments was significantly higher compared to the titanium abutment group $(\mathrm{P}=0.002)$.

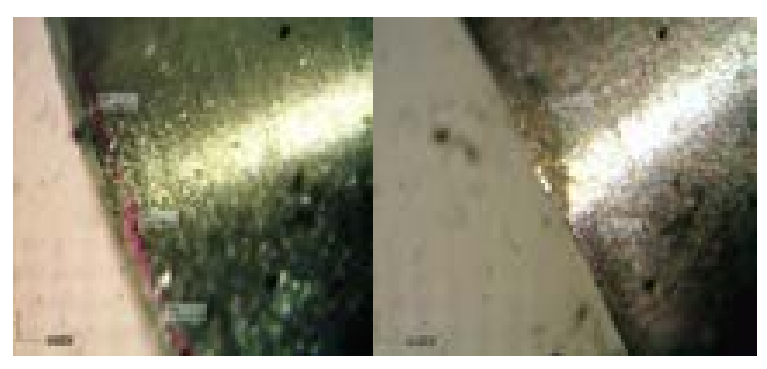

Figure 4a: Fuchsine penetration in samples of titanium abutment group at $\times 75$ magnification of electron microscope

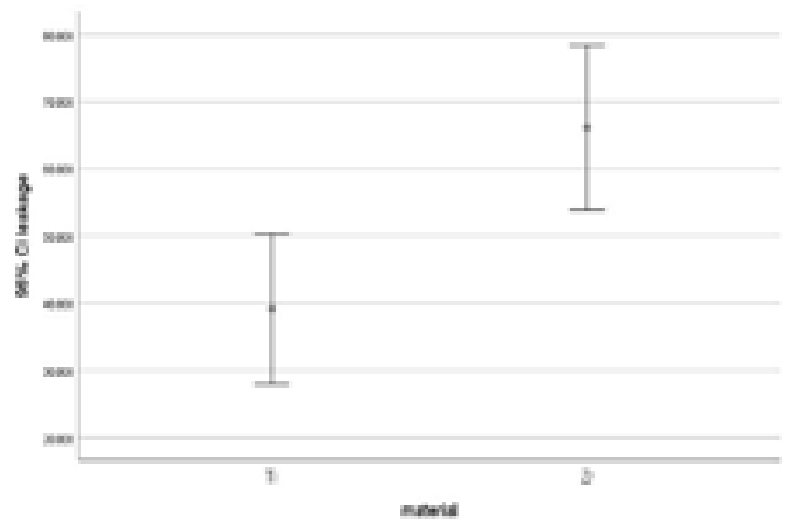

Diagram 1: Mean microleakage in zirconia and titanium abutments after cyclic loading 
Table 2. Mean and standard deviation (SD) for microleakage after cyclic loading

\begin{tabular}{|c|c|c|c|c|c|}
\hline & Abutment & Number & Minimum & Maximum & Microleakage \\
\hline Zirconia & $\begin{array}{c}\text { Microleakage after } \\
\text { applying force }\end{array}$ & 6 & $53.930 \mu \mathrm{m}$ & $\begin{array}{c}85.964 \\
\mu \mathrm{m}\end{array}$ & $\begin{array}{c}66.08 \pm 11.66 \\
\mu \mathrm{m}\end{array}$ \\
\hline Titanium & $\begin{array}{c}\text { Microleakage after } \\
\text { applying force }\end{array}$ & 6 & $28.320 \mu \mathrm{m}$ & $\begin{array}{c}51.557 \\
\mu \mathrm{m}\end{array}$ & $\begin{array}{c}39.17 \pm 10.65 \\
\mu \mathrm{m}\end{array}$ \\
\hline & P-Value & \multicolumn{4}{|c|}{$\mathrm{P}<0.002$} \\
\hline
\end{tabular}

\section{Discussion:}

In this in-vitro study, the microleakage of titanium and zirconia abutments was investigated under $75 \mathrm{~N}$ oblique cyclic loading at an angle of $30 \pm 2^{\circ}$ to the longitudinal axis of the implant at a frequency of $1 \mathrm{~Hz}$ in 500,000 cycles. Titanium abutments showed significantly less microleakage than zirconia abutments.

One of the basic considerations when placing implant-based restorations is to minimize the number of bacteria that colonize the transmucosal portion of the restoration. ${ }^{(32)}$ Most implants today have two main parts, including the endosteal part and the transmucosal part (abutment). When the abutment is placed on the implant, it creates a microspace called the IAI. ${ }^{(2)}$ Studies have shown that oral microbiota can proliferate in this space and cause inflammation in the peri-implant tissues and adjacent bone. ${ }^{(2,33)}$ Bacterial colonization in the IAI depends on several factors, including the precise adjustment between the implant components, the torque between these components, and the force exerted on the implants when placed in the oral cavity and function. ${ }^{(1)}$ In the present study, to simulate the clinical conditions of occlusal force transfer in the oral environment on the abutments, the oblique force was used as cyclic loading. A $30^{\circ}$ angle of force was used to simulate the occlusal relationship and functional forces applied to the roots of maxillary and mandibular incisors. ${ }^{(34)}$ When transmitting masticatory forces to the abutment-restoration assembly, the lateral component of force is responsible for creating bending moments. Non-axial forces on the anterior maxillary teeth also cause more stress in the facial and lingual surfaces of the IAI. ${ }^{(34)}$ Therefore, in the present study, cyclic loading at an angle of $30^{\circ}$ and a frequency of $1 \mathrm{~Hz}$ in 500,000 cycles, which is equivalent to 20 months of human masticatory force, was used. In other studies, similar conditions have been used to study microleakage in the IAI (Larrucea et al, 2018; Koutouzis et al, 2016; Do Nascimento et al, 2012). . $2,4,15)^{-}$

In the present study, it was observed that despite observing all aspects, such as proper torque when securing the abutment, microleakage was present in both zirconia and titanium abutments. Contrary to the findings of the present study, Koutouzis et al (2014) stated that Morse taper implant systems show partial bacterial infiltration into the IAI..$^{(35)}$ By causing microvoments in the IAI, dynamic loading creates a pumping effect and increases bacterial penetration. ${ }^{(36)}$ On the other hand, in agreement with the present study, Harder et al (2012) and Tripodi et al (2015) reported that conical IAI did not prevent microleakage at the molecular level even under unloaded conditions. ${ }^{(14,37)}$ In general, studies have shown that implants with Morse taper connection show 
more resistance to bacterial microleakage compared to external hexagon implants, but in any case, some microleakage will be present at the molecular level despite observing all the conditions. ${ }^{(38)}$ Therefore, due to less microleakage reported in previous studies, Morse taper implants were used in the present study. ${ }^{(5)}$

Various in-vivo studies have shown the potential for microbial leakage from IAI under loading and non-loading conditions (Baggi et al, 2013; Gherlone et al, 2016). ${ }^{(18,39)}$ Despite this, in-vitro studies are useful for understanding the dynamics of the IAI and thus enhancing the microspace design. In a study by Martin-Gili et al (2015), it was found that external hexagon implants had the highest microbial penetration into the IAI under load and non-load conditions. ${ }^{(40)}$ This partly explains the histological findings of in-vivo studies of increased connective tissue inflammation around external hexagon implants.

In the present study, it was observed that zirconia abutments exhibited significantly more microleakage after oblique cyclic loading compared to titanium abutments. Findings similar to the present study have been reported in various studies. In a study by Smith and Turkyilmaz (2014), it was observed that in external hexagon implants with titanium abutment, the size of microgap was significantly smaller compared to zirconia abutment, and when the torque increased from 20 N.cm to 35 N.cm, the microgap size of zirconia abutment decreased. ${ }^{(23)}$ Comparing titanium and zirconia abutments under loading conditions, Cavusoglu et al (2014) reported that the IAI showed more microleakage in zirconia abutments that had progressed toward the screw joint. ${ }^{(41)}$ The researchers attributed this finding to the fact that IAI wear in zirconia abutments was 8.3 times that of titanium abutments. They concluded that zirconia/titanium IAIs were more susceptible to abrasion and deformation of the implant neck than conventional titanium/titanium IAIs. In the study by Abdelhamed et al (2015), it was found that the microleakage of zirconia abutment when using 15 N.cm torque to secure the abutment was significantly higher compared to 25 N.cm torque. ${ }^{(31)}$ Comparing the findings with similar studies, it can be concluded that more microleakage observed in zirconia abutments is probably due to fatigue, more wear of compo- nents, and inhibition of mating in zirconia abutments, which lead to more leakage of fuchsine dye.

Several recent studies have reported conflicting findings with the current study. Rismanchian et al (2012) did not find any significant differences in microleakage between cast on, castable, solid, and synocta abutments. ${ }^{(17)}$ In a study by Larrucea et al (2018), microgaps associated with zirconia abutments were significantly smaller than those of titanium abutments. ${ }^{(15)}$ The discrepancy between these studies and the current study may be due to differences in how zirconia is sintered, different implant systems and laboratory conditions, and force applied. In general, the findings of this study show that microleakage following oblique cyclic loading in zirconia abutments is significantly higher than that of titanium abutments. Therefore, zirconia abutments should be used with caution in situations where a large occlusal force is expected on the abutment. There is a need for more controlled clinical research to facilitate the choice between zirconia and titanium abutments.

One of the limitations of the present study was the impossibility of investigating common mechanical problems, such as preload reduction, screw loosening, and abutment rotation, which of course were not among the objectives of the present study. It has also been suggested that zirconia aging leads to the progressive conversion of the tetragonal phase to the monoclinic phase, which negatively affects the mechanical properties, ${ }^{(42,43)}$ this issue is suggested in future studies for further investigation.

\section{Conclusion:}

Considering the limitations, the findings of this study show that microleakage following oblique cyclic loading varies depending on the type of abutment. Titanium abutments showed significantly less microleakage than zirconia abutments. It seems that more in-vivo and in-vitro studies are needed to investigate the microleakage of zirconia abutments and its effect on the peri-implant tissues.

\section{Acknowledgements:}

We greatly appreciate the support of the Vice Chancellor for Research, Faculty of Dentistry, 
Islamic Azad University of Medical Sciences, Tehran, Iran. It should be noted that this study is the result of a dissertation with the design code of $193 / \mathrm{t}$.

\section{References:}

1. Nascimento C, Ikeda LN, Pita MS, Pedroso e Silva RC, Pedrazzi V, Albuquerque RF, et al. Marginal fit and microbial leakage along the implantabutment interface of fixed partial prostheses: An in vitro analysis using Checkerboard DNA-DNA hybridization. J Prosthet Dent. 2015;114(6):8318.

2. Koutouzis T, Gadalla H, Lundgren T. Bacterial Colonization of the Implant-Abutment Interface (IAI) of Dental Implants with a Sloped Marginal Design: An in-vitro Study. Clin Implant Dent Relat Res. 2016;18(1):161-7.

3. Berberi A, Tehini G, Rifai K, Bou Nasser Eddine F, El Zein N, Badran B, et al. In vitro evaluation of leakage at implant-abutment connection of three implant systems having the same prosthetic interface using rhodamine B. Int J Dent. 2014;2014:351263.

4. do Nascimento C, Miani PK, Pedrazzi V, Goncalves RB, Ribeiro RF, Faria AC, et al. Leakage of saliva through the implant-abutment interface: in vitro evaluation of three different implant connections under unloaded and loaded conditions. Int J Oral Maxillofac Implants. 2012;27(3):55160.

5. Aloise JP, Curcio R, Laporta MZ, Rossi L, da Silva AM, Rapoport A. Microbial leakage through the implant-abutment interface of Morse taper implants in vitro. Clin Oral Implants Res. 2010;21(3):328-35.

6. D'Ercole S, Tripodi D, Ravera L, Perrotti V, Piattelli A, Iezzi G. Bacterial leakage in Morse Cone internal connection implants using different torque values: an in vitro study. Implant Dent. 2014;23(2):175-9.

7. Assenza B, Tripodi D, Scarano A, Perrotti V, Piattelli A, Iezzi G, et al. Bacterial leakage in implants with different implant-abutment connections: an in vitro study. J Periodontol. 2012;83(4):491-7.

8. Tallarico M, Fiorellini J, Nakajima Y, Omori Y, Takahisa I, Canullo L. Mechanical Outcomes, Microleakage, and Marginal Accuracy at the Implant-Abutment Interface of Original versus
Nonoriginal Implant Abutments: A Systematic Review of In Vitro Studies. BioMed Res Int. 2018;2018:2958982.

9. D'Ercole S, Scarano A, Perrotti V, Mulatinho J, Piattelli A, Iezzi G, et al. Implants with internal hexagon and conical implant-abutment connections: an in vitro study of the bacterial contamination. J Oral Implantol. 2014;40(1):30-6.

10.Al-Jadaa A, Attin T, Peltomaki T, Schmidlin PR. Comparison of three in vitro implant leakage testing methods. Clin Oral Implants Res. 2015;26(4):e1-e7.

11.Zipprich H, Miatke S, Hmaidouch R, Lauer HC. A New Experimental Design for Bacterial Microleakage Investigation at the ImplantAbutment Interface: An In Vitro Study. Int J Oral Maxillofac Implants. 2016;31(1):37-44.

12.Khorshidi H, Raoofi S, Moattari A, Bagheri A, Kalantari MH. In Vitro Evaluation of Bacterial Leakage at Implant-Abutment Connection: An 11-Degree Morse Taper Compared to a Butt Joint Connection. Int J Biomater. 2016;2016:8527849. 13.Passos SP, Gressler May L, Faria R, Ozcan M, Bottino MA. Implant-abutment gap versus microbial colonization: Clinical significance based on a literature review. J Biomed Mater Res B Appl Biomater. 2013;101(7):1321-8.

14.Tripodi D, D'Ercole S, Iaculli F, Piattelli A, Perrotti V, Iezzi G. Degree of bacterial microleakage at the implant-abutment junction in Cone Morse tapered implants under loaded and unloaded conditions. J Appl Biomater Funct Mater. 2015;13(4):e367-71.

15.Larrucea C, Conrado A, Olivares D, Padilla C, Barrera A, Lobos O. Bacterial microleakage at the abutment-implant interface, in vitro study. Clin Implant Dent Relat Res. 2018;20(3):360-7. 16. Alves DC, Carvalho PS, Martinez EF. In vitro microbiological analysis of bacterial seal at the implant-abutment interface using two morse taper implant models. Braz Dent J. 2014;25(1):4853.

17.Rismanchian M, Hatami M, Badrian H, Khalighinejad N, Goroohi H. Evaluation of microgap size and microbial leakage in the connection area of 4 abutments with Straumann (ITI) implant. J Oral Implantol. 2012;38(6):677-85.

18. Gherlone EF, Cappare P, Pasciuta R, Grusovin MG, Mancini N, Burioni R. Evaluation of resistance against bacterial microleakage of a 
new conical implant-abutment connection versus conventional connections: an in vitro study. New Microbiol. 2016;39(1):49-56.

19. Cardoso M, Sangalli J, Koga-Ito CY, Ferreira LL, da Silva Sobrinho AS, Nogueira L, Jr. Abutment Coating With Diamond-Like Carbon Films to Reduce Implant-Abutment Bacterial Leakage. J Periodontol. 2016;87(2):168-74.

20.Lemos CAA, Verri FR, Bonfante EA, Santiago Júnior JF, Pellizzer EP. Comparison of external and internal implant-abutment connections for implant supported prostheses. A systematic review and meta-analysis. J Dent. 2018;70:1422.

21.Leonhardt Å, Renvert S, Dahlén G. Microbial findings at failing implants. Clin Oral Implants Res. 1999;10(5):339-45.

22.Dias ECLCM, Silva-Olívio IRT, Coppedé A, Groisman M. Assessment of Bacterial Leakage at the Implant-Abutment Interface of Internal and External Connection Implants: An In Vitro Study. Dent Health Curr Res. 2016;2:2. doi:10.4172/2470-0886.1000115.

23.Smith NA, Turkyilmaz I. Evaluation of the sealing capability of implants to titanium and zirconia abutments against Porphyromonas gingivalis, Prevotella intermedia, and Fusobacterium nucleatum under different screw torque values. J Prosthet Dent. 2014;112(3):561-7.

24.Peruzetto WM, Martinez EF, Peruzzo DC, Joly JC, Napimoga MH. Microbiological Seal of Two Types of Tapered Implant Connections. Braz Dent J. 2016;27(3):273-7.

25.Pimentel AC, Manzi MR, Sartori SG, da Graca Naclerio-Homem M, Sendyk WR. In vivo effectiveness of silicone gel sheets as barriers at the inner microgap between a prosthetic abutment and an external-hexagon implant platform. Int J Oral Maxillofac Implants. 2014;29(1):1216.

26. Alikhasi M, Monzavi A, Bassir SH, Naini RB, Khosronedjad N, Keshavarz S. A comparison of precision of fit, rotational freedom, and torque loss with copy-milled zirconia and prefabricated titanium abutments. Int J Oral Maxillofac Implants. 2013;28(4):996-1002.

27.Butignon LE, Basilio Mde A, Pereira Rde P, Arioli Filho JN. Influence of three types of abutments on preload values before and after cyclic loading with structural analysis by scanning elec- tron microscopy. Int J Oral Maxillofac Implants. 2013;28(3):e161-70.

28. Gehrke SA, Poncio da Silva PM, Calvo Guirado JL, Delgado-Ruiz RA, Dedavid BA, Aline Nagasawa $M$, et al. Mechanical behavior of zirconia and titanium abutments before and after cyclic load application. J Prosthet Dent. 2016;116(4):529-35.

29.Mishra SK, Chowdhary R, Kumari S. Microleakage at the Different Implant Abutment Interface: A Systematic Review. J Clin Diagn Res. 2017;11(6):ZE10-ZE5.

30.Chang B, Goldstein R, Lin CP, Byreddy $\mathrm{S}$, Lawson NC. Microleakage around zirconia crown margins after ultrasonic scaling with selfadhesive resin or resin modified glass ionomer cement. J Esthet Restor Dent. 2018;30(1):73-80. 31. Abdelhamed MI, Galley JD, Bailey MT, Johnston WM, Holloway J, McGlumphy E, et al. A Comparison of Zirconia and Titanium Abutments for Microleakage. Clin Implant Dent Relat Res. 2015;17 Suppl 2:e643-51.

32.Black DL, Turkyilmaz I, Lien W, Chong CH. Evaluation of the Sealing Capability of the Internal Conical Connections of Implants with Titanium and Zirconia Abutments. J Contemp Dent Pract. 2017;18(10):915-22.

33. Hsu YT, Mason SA, Wang HL. Biological implant complications and their management. J Int Acad Periodontol. 2014;16(1):9-18.

34. Yuzugullu B, Avci M. The implant-abutment interface of alumina and zirconia abutments. Clin Implant Dent Relat Res. 2008;10(2):113-21.

35.Koutouzis T, Mesia R, Calderon N, Wong F, Wallet $\mathrm{S}$. The effect of dynamic loading on bacterial colonization of the dental implant fixtureabutment interface: an in vitro study. J Oral Implantol. 2014 Aug;40(4):432-7.

36. Hermann JS, Schoolfield JD, Schenk RK, Buser D, Cochran DL. Influence of the size of the microgap on crestal bone changes around titanium implants. A histometric evaluation of unloaded non-submerged implants in the canine mandible. J Periodontol. 2001;72(10):1372-83.

37. Harder S, Quabius ES, Ossenkop L, Kern M. Assessment of lipopolysaccharide microleakage at conical implant-abutment connections. Clin Oral Investig. 2012;16(5):1377-84.

38. Mishra SK, Chowdhary R, Kumari S. Microleakage at the Different Implant Abutment In- 
terface: A Systematic Review. J Clin Diagn Res. 2017;11(6):ZE10-ZE5.

39. Baggi L, Di Girolamo M, Mirisola C, Calcaterra R. Microbiological evaluation of bacterial and mycotic seal in implant systems with different implant-abutment interfaces and closing torque values. Implant Dent. 2013;22(4):344-50. 40.Martin-Gili D, Molmeneu M, Fernandez M, Punset M, Giner L, Armengou J, et al. Determination of fluid leakages in the different screwretained implant-abutment connections in a mechanical artificial mouth. J Mater Sci Mater Med. 2015;26(7):211.

41.Cavusoglu Y, Akca K, Gurbuz R, Cehreli MC. A pilot study of joint stability at the zirconium or titanium abutment/titanium implant interface. Int J Oral Maxillofac Implants. 2014;29(2):338-43. 42. Nakamura K, Kanno T, Milleding P, Ortengren U. Zirconia as a dental implant abutment material: a systematic review. Int J Prosthodont. 2010;23(4):299-309.

43.Naser mostofy S, Jalalian E, Valaie $\mathrm{N}$, Mohtashamrad Z, Haeri A, Bitaraf T. Study of the Effect of GapSeal on Microgap and Microleakage in Internal Hex Connection After Cyclic Loading. J Res Dentomaxillofac Sci. 2019; 4 (3) :36-42.

Please cite this paper as: Naser mostofy S, Zarbakhsh A, Alaei M, Bitaraf T. Evaluation of the Effect of Zirconia and Titanium Abutments on Microleakage of Implant-Abutment Interface Under Oblique Cyclic Loading In Vitro. J Res Dentomaxillofac Sci.2020;5(3):15-23 